\title{
Better Segmentation of Enterprise Modelling Governance through Usage Perspectives
}

\author{
Frank Wolff \\ DHBW-Mannheim, Information Science, Coblitzallee. 1-9, \\ 68163 Mannheim, Germany \\ Frank.Wolff@dhbw-mannheim.de
}

\begin{abstract}
Enterprise modelling is an endeavor that involves many different stakeholders in a company and requires a long-term approach to reap major benefits. Due to their differing main tasks the stakeholders frequently pursue deviating goals. Therefore, an appropriate management of the stakeholders is considered a success factor for enterprise modelling. The goals of the stakeholders in respect of an enterprise model and their role in the modelling process are crucial for this distinction. The differentiation can be facilitated by generic goals and a scheme that accounts for influences like variants in the size of companies and the impact of enterprise modelling on business. The application of the outlined procedure is exemplified with an illustrative case of a chemical supplier.
\end{abstract}

Keywords: Enterprise modelling, Modelling goals, Modelling governance, Participants involvement, Stakeholders.

\section{Introduction}

Enterprise modelling ${ }^{1}$ integrates knowledge from many different domains in a company. Central are information on business processes, organizational relationships and IT-systems. Enterprise models support management with overall information but they also supply specialists with details for their concerns (e.g. [1], [2], [3]). Thereby, an enterprise model serves a considerable number of purposes. The goals that reflect the purposes to create and use an enterprise model in practice vary widely. Some goals are of more operational nature, e.g. to supply IT-service desk employees with an overview on the network infrastructure. Other purposes have strategic impact, e.g., if a company uses its process models to improve the integration of acquired companies or if it applies the models as a blueprint to establish new subsidiaries and production lines faster. The high potential benefits convinced many companies to start enterprisewide modelling activities.

\footnotetext{
${ }^{1}$ In this paper the term enterprise modelling (EM) is used. This includes enterprise architecture modelling (EAM). EAM is somehow more focused on IT-infrastructures but the similarity with EM is quite substantial as both cover whole organizations and integrate the concerns of management, business operations and IT.
} 
In the beginning of enterprise modelling, the appropriate modelling methodology and a convenient tool were focused by research (e.g. [3], [4]). Now these concepts and technologies have matured considerably. But the status of enterprise models in many if not most companies is still not regarded as satisfactory [5]. This has been reported for some time and has changed little as the author of this paper noted at a number of recent practitioner conferences.

Many suppose the challenge is rooted in the interaction of the participants of enterprise modelling. Often the organization of the modelling process is very optimistic and does not account for the different perception of the diverse participants e.g. the providers and users of information [6]. Also sometimes organizational constraints hinder the effective usage of enterprise models [7].

Major challenges are 1) that to collect information and reflect them in the enterprise model collaboration of numerous specialists is required, 2) many potential benefits can only be realized over a longer time period and 3) enterprises are not static but transform frequently due to market and technological changes. So a long-term approach is advisable and as different groups of people are involved an active management or governance of enterprise modelling is required [8].

Different schemes have been proposed for a better governance of enterprise modelling (e.g. [9] or [10]). They provide a good outline on the essential elements for general governance activities. But they lack appropriate guidance to support the practitioner or researcher with practical knowledge how to adapt the governance and cope with the individual conditions of a particular company, in particular, its goals for the enterprise model and the different stakeholders involved in the modelling processes.

This paper deals with this shortcoming. It presents a compilation of generic goals for enterprise modelling and takes a closer look on the typical differentiation of enterprise modelling perspectives and other stakeholder models. These elements will be integrated in the dedicated concept of usage perspectives, which assists organizations to segment its management of enterprise modelling activities individually. This is important to create efficient and effective governance structures. Theoretical models tend usually to either simplify this aspect too much or build highly particularized structures [11]. To cater for different enterprise sizes and individual goals an appropriate integration is required.

\section{Interests in Enterprise Models}

People from distinct departments involved in enterprise modelling processes usually pursue different goals. Those goals are shaped by the individual work context of the participants and to a lesser part the overall goals of the company. The differences in their interests frequently inhibit an ideal creation and usage of an enterprise model, e.g. because it is not completed, updated as necessary or persists in a fragmented state.

To support the involved employees adequately, control the status of models and modelling processes diverse aspects must be accounted for. This topic has been 
addressed before mainly concentrating on either: a) goals for enterprise modelling, b) perspectives on enterprise models or c) analysis of involved stakeholders.

\subsection{Goals for Enterprise Modelling}

Theory and publications of providers of enterprise modelling tools stress the advantages and deduce a number of valuable usages of the models. They are often formulated as goals for enterprise modelling. The overview in Fig. 1 depicts a systemized compilation of these goals from literature (e.g. [4], [12], [13], [14]). It is based on an analysis of 18 sources from literature on enterprise modelling directly or specific kinds of modelling which are parts of enterprise models [15]. One important insight of the study was that modelling goals are usually listed without regard to the different extent of their potential effects on the company operations and the business. Some objectives are directly focused on certain actions of participants and others aim at broader effects on the business of a company.

The analysis revealed that goals for enterprise modelling range from strategic issues (e.g. easing integration of other companies, higher flexibility of a company) to the level of direct support of working activities (e.g. documentation or automation of work steps). Some goals are positioned at intermediate levels (e.g. improving coordination, better system integration or the reuse of concepts). Last but not least a model can support directly tasks like communication e.g. in projects or provide required documentation

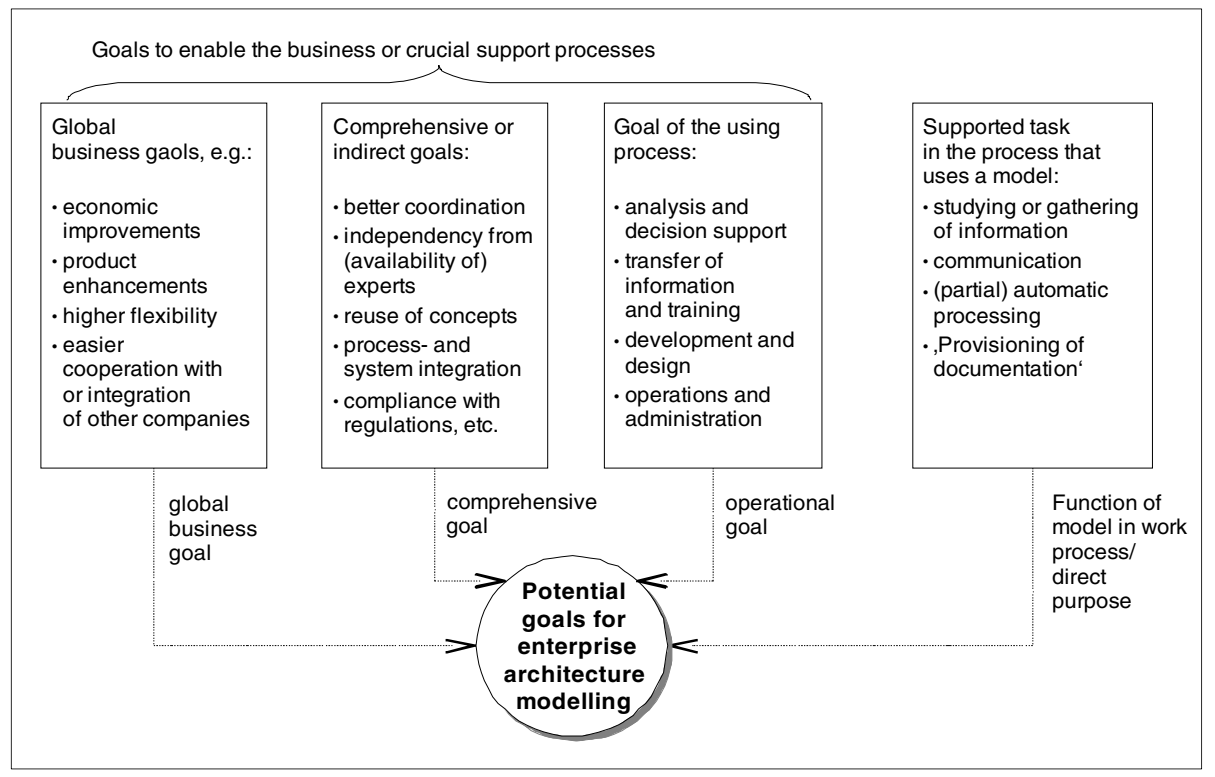

Fig. 1. Goals for enterprise architecture modelling with different levels of organizational effect 
The goals in Fig. 1 are generic. In practice they will be connected in various ways. Crucial is the relation to a domain knowledge or model content that is of interest for people in a company, e.g. business processes or IT applications. Then usually the goals have interrelationships e.g. that for the global business goal of higher flexibility the realization of a better coordination and process integration is required. These latter then help employees directly in development and design of new processes and systems.

The above presented goals are related to substantial advantages of enterprise architecture models. Considering the typical timeframe and potential pitfalls in enterprise transformation processes it is presumably extremely valuable for a company in such situations to achieve some of the above listed goals by utilizing enterprise models. Nevertheless, even companies that start enterprise modelling initiatives rarely succeed in building and updating all parts of a comprehensive enterprise model [7], [8].

Many obstacles for a smooth modelling process originate from the diverse participants required for a modelling effort of this kind. Some individuals only have very constrained knowledge. So they may have problems to contribute effectively to the overall model. Others could easily produce single parts of the enterprise model but will not reap any benefit from the model as they do not need the information. Another aspect is that for a company it is usually much easier and more economical if the information is documented in the model while the information is well at hand. It is often very dear and costly to reproduce it later when the knowledgeable person has moved to another position or is not available for other reasons.

The above outlined combinations and relationships of multiple goals of involved persons can be analyzed by using goal modelling techniques like KAOS or iStar to identify supporting and contradicting goals [16]. These approaches promise many advantages in critical or perplexing situations. Nevertheless, in this paper a more basic maybe pragmatic approach is chosen, which focuses on the important stakeholder groups for an enterprise modelling endeavor.

\subsection{Consideration of Generic Perspectives and Stakeholder Groups in Enterprise Modelling}

In most enterprise modelling methods the participants are differentiated by perspectives or views. Very prominent is the distinction into a management, a business and an information systems perspective (e.g. [2], [3]). This focusses on very strikingly different involved groups but will not easily scale up or reflect distinct goals stemming e.g. from particular crucial customer groups.

This issue has been taken up by the research on stakeholders in enterprise models in recent years [17]. The consideration of the stakeholders in an activity is vital if desired interaction can only be reached by many parties interacting in a common direction [18]. The major objective of enterprise modelling is the provisioning of relevant information in a structured form. Therefore, information needs are one determinant shaping stakeholder groups [19]. An adequate representation of stakeholders is fundamental to cater for the requirements of the group so that essential 
modelling is done. While the stakeholder analysis supports a very detailed analysis of participating groups, it has been noted that this does not fit for many, especially medium sized enterprises [20]. A more flexible way will be presented in the following section integrating the concepts of goals and stakeholders in usage perspectives.

\section{Focusing on Usage Perspectives of Enterprise Models}

The problem of sufficient motivation and knowledge to model is quite subtle because the collision of interest usually differs for each of the departments involved in modelling and usage of enterprise models. E.g. the controlling department only has some specialized processes to model but needs some detailed information about numerous resources and processes all over the company. The department of IT is accustomed to work with conceptual models. But regularly it is under high time pressure. So IT-departments often hesitate to invest scarce manpower into a concerted enterprise modelling approach. Other departments like e.g. warehouse are unfamiliar with conceptual models. This also may prevent an easy adoption and inclusion of their procedures, tools and systems into an enterprise model.

The concept of usage perspectives ${ }^{2}$ comprises these distinct aspects and helps to establish a balanced structure of groups concerned with enterprise modelling which is adapted to a company's characteristics and can also handle the combination of different partial views. This balancing and integration is necessary to foster shared cognition [21] which is a prerequisite to achieve the overall goals of an enterprise model [8].

\subsection{Elements of Usage Perspectives}

As it has been argued the interests but also problems to create the parts of an enterprise model vary for the diverse groups involved. To prepare necessary subsistence it is indispensable to identify groups with similar characteristics and interests. Fig. 2 depicts criteria to distribute the groups involved in modelling appropriately into utilization perspectives.

The distribution is based on two perspectives a) the overall business perspective and $b$ ) the modelling perspective. The business perspective determines the goals for using models and thereby modelling. The modelling perspective is rooted in the depicted domain. It is related to the typical knowledge of the people working in the domain. The business and the modelling perspectives are important for the context of work. The elements of the context of work may stem initially from the generic characteristics of modelling context and the business goals. But it should be noted that in many cases also other conditions impact the interest and cognition of participants e.g. the kind of education, nature of work, geographical or cultural traits. By

2 Alternatively to the term usage perspective it was considered to name the concept involvement perspective. But this was rejected as the focus on the benefits was perceived to be decisive. 
clustering groups of people along their context of work and their typical modelling knowledge important stakeholders in regard of enterprise models can be identified.

As basis the individual characteristics and goals of the stakeholders are discerned. Then the similarities of goals and stakeholder characteristics are the used to discover common perspectives. This analysis is balanced by considering an appropriate number of usage perspectives for an enterprise. This number depends on the size and the strategic importance of enterprise modelling for the company. Besides basic utilization perspectives which cover one subject area of a company, e.g. the production of a major product line, also other perspectives are allowed for. If model information from different perspectives is required for an additional purpose interrelated usage perspectives are created.

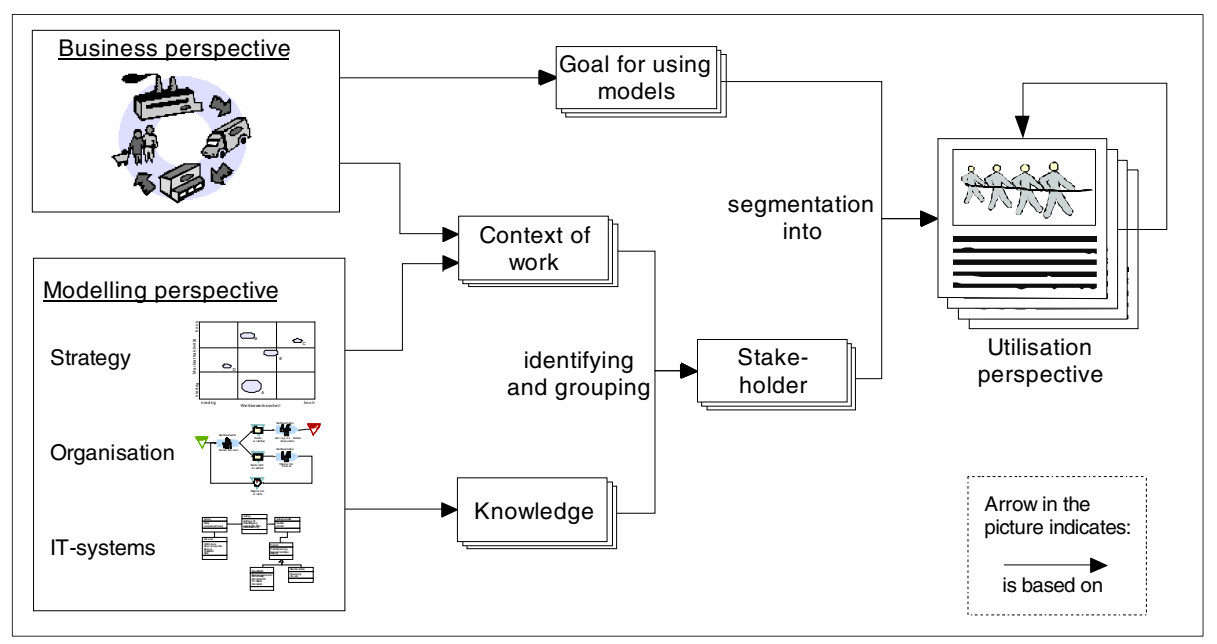

Fig. 2. Criteria to distribute enterprise architecture modelling into utilization perspectives

\subsection{Management of the Enterprise Modelling Process}

While good enterprise models appear to be simple and intelligible their creation and actualization is quite a perplexing process. The different involved groups are one major challenge. This is due to many cognitive, political and organizational issues [22]. Another aspect is the distribution of changes in time but also in related entities of an enterprise. Also effort for data collection can be very high and data quality is often rather low [11].

All these characteristics call for an active management or governance of enterprise modelling processes ([10], [15]). One main duty of this governance would be to ensure that pending updates for models activate relevant triggers. Besides organizational arrangements also technical coupling is an important force for up-todate and correct enterprise models [11]. This applies very much for automatic conversion of systems data into models and vice versa. But also connection between 
different spheres of modelling is of high interest in practice (e.g. business processes and IT-Infrastructure).

The utilization perspectives help an organization to a) discover conflicts of interest between participants and/or company goals, and subsequently to resolve them, b) control the current required update of an enterprise architecture model and c) make up a more realistic assessment of options to model its enterprise ([15], [23]). An appropriately adopted organization has been identified to have high influence on the prospects to reap the benefits from an enterprise model [5].

\subsection{Example Distribution of Usage Perspectives}

In this section an illustrative example of a chemical supplier company is presented. Outline of the example: The chemical company has two major divisions. One is working for the medical industry and the other is distributing a wide range of basic chemical substances to other non-regulated industries. Some subsidiaries have been founded abroad for doing better business in other countries. The subsidiaries often also profit from lower wages or material prices. Due to their success, more foreign affiliations are planned.

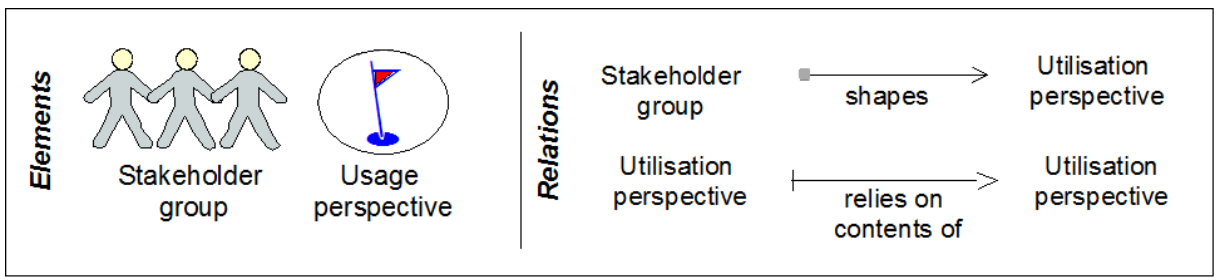

Fig. 3. Elements (left side) and relations (right side) of the usage perspectives structure diagram

The example will be depicted in a diagram which may be connected to other models for control of enterprise modelling endeavors (e.g. in [24]). The model is composed of two main element types - 1) usage perspectives and 2) stakeholder groups (see Fig. 3). The elements are connected through 2 types of relations. ${ }^{3}$ The first relation serves to reflect which stakeholder groups are involved in a utilization perspective. The second relation represents the dependency of certain usage perspectives on contents of models created and updated by stakeholders from other usage perspectives. ${ }^{4}$

\footnotetext{
3 An integration relation for one or more comprehensive perspectives is possible but not in the scope of this paper.

${ }^{4}$ A tool to model Usage Perspectives can be downloaded from the website of the Open Models Initiative - www.openmodels.at. The modelling tool is contained in the package for Evaluation Chains (EC) and includes dedicated reference models for the assessment of enterprise modelling activities.
} 


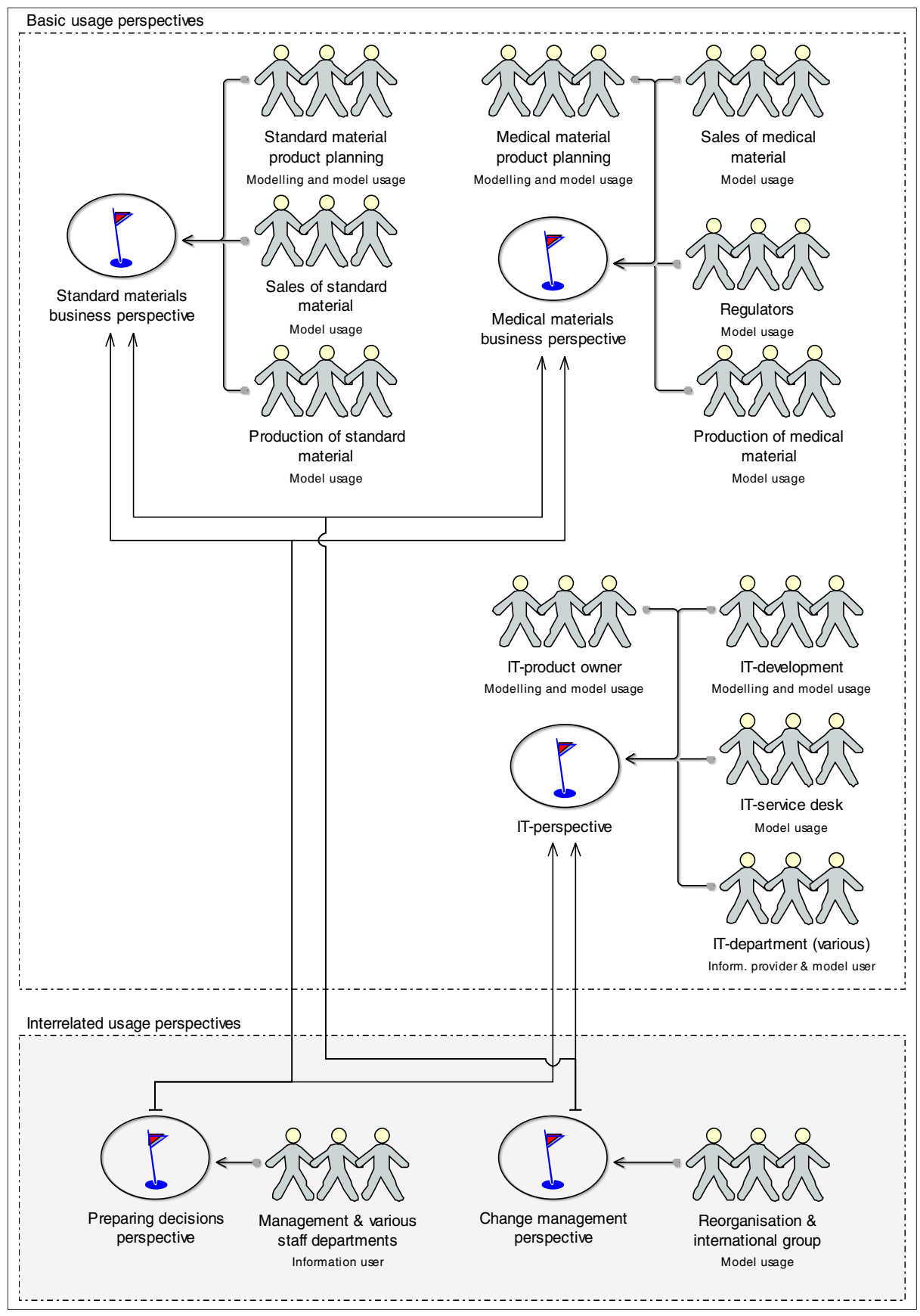

Fig. 4. Illustrative example for Usage Perspectives of a supplier for chemical base materials 
While basic usage perspectives can be analyzed and managed on their own the depending usage perspectives require a more comprehensive consideration. However, it should be noted that likewise basic usage perspectives may be composed of different groups of stakeholders. These groups are either differentiated by their role in the modelling process (e.g. knowledge provider, modeler or model user) or by their goals for using the models. In the presented diagram goals are only stored in the background. However, to some extent they are reflected in the label of the stakeholder group. The underlying intention was to create a distinct overview on the groups without too many details.

The separation of usage perspectives for the example chemical company is presented in Fig. 4. It differentiates five main usage perspectives, a) Standard materials business perspective, b) Medical materials business perspective, c) ITperspective, d) Preparing decisions perspective and e) Change management perspective. The foundational perspectives for the enterprise model that directly create business models are depicted on top of the diagram $(\mathrm{a} \& \mathrm{~b})$. The IT-perspective (c) is in the center and the two perspectives which do not create models but are using information or models from the others are positioned at the bottom (d\& e).

The two business perspectives are structurally very similar and only differentiated by the additional stakeholder group of regulators. This may seem to be only a small variance. But due to the risks to human life the obligations in medical production lines are very strict and have severe impact on the organization and related procedures in the domain. Therefore, it is reasonable to manage the two business lines in separate perspectives.

In the IT-perspective four main stakeholder groups cooperate. On the top the active modelling groups of IT-product owners and IT-development are positioned. The models of the IT are used by all stakeholders of the IT-perspective. Especially the ITservice desk considerably relies in his work on the models provided by the modelling stakeholder groups. As technical details are known only by some specialists it is often essential that some of the other members of the IT-department (various) must supply additional information.

The goal analysis of the stakeholders is not represented in the diagram directly but is underlying the example case. As explained in chapter 2.1. the goals regularly are compounds of more than one generic goal. E.g. the IT-service desk requires information independent from the availability of certain specialists. They use the information in their operations processes which entail tasks like studying and gathering of information. The reorganization \& international group, on the other hand, often pursues goals, like higher flexibility, reuse of concepts, development and design of new entities all relying on efficient communication between the involved partners. This argumentation demonstrated the principles how to distinguish and recombine the different characteristics to segment usage perspective for the governance of enterprise modelling. ${ }^{5}$

\footnotetext{
${ }^{5}$ The model in the diagram had been restricted by the available space. In a bigger company typically more distinctions could be advisable in regard of the difference between production and administration in the business perspectives. Similarly in the IT domain, the operations and the development groups in many cases focus on different areas and contents of the enterprise model.
} 


\section{Conclusion and Further Research}

Enterprise modelling in companies is frequently faced with problems due to difficulties in the interaction of involved stakeholders. The problems often surface only late because the social implications of these large-scale complex endeavors are not directly visible [8]. The segmentation proposed in this paper serves to organize and control the various activities of enterprise modelling by embracing many of these impeding factors. The proposed procedure adapts to small enterprises with only a handful of usage perspectives up to very large enterprises with perhaps 40 or more usage perspectives. It is fundamental for enterprise modelling that the organizational setting secures that the actors and participants for their part can be fully involved in their modelling, and are not hindered by other interests.

Further research in usage perspectives is planned to be twofold: a) direct examination of the segmentation in more companies to analyze the effects of segmentation in governance on the abilities of an organization to control its achievements with enterprise models and b) further development of a modelling methodology to support the analysis of the relationships between goals, rationales, decisions and organizational contexts in enterprise modelling (comp. [25]).

\section{References}

1. Braun, C., Winter, R.: A Comprehensive Enterprise Architecture Metamodel. In: Desel, J., Frank, U. (eds.) Proceedings of the Workshop in Klagenfurt 2005 Enterprise Modelling and Information Systems Architectures, pp. 64-79. GI LNI P- 75, Bonn (2005)

2. Lankhorst, M., et al.: Enterprise Architecture at Work - Modelling, Communication and Analysis, 3rd edn. Springer, Berlin (2013)

3. Frank, U.: Multi-Perspective Enterprise Modeling (MEMO): Conceptual Framework and Modeling Languages. In: 35th (HICSS), Big Island, pp. 1-10. IEEE Computer (2002)

4. Davis, R.: Business Process Modelling with ARIS. Springer, London (2001)

5. Foorthuis, R.M., van Steenbergen, M., Mushkudiani, N., Bruls, W., Brinkkemper, S., Bos, R.: On Course, But Not There Yet: Enterprise Architecture Conformance and Benefits in Systems Development. In: Proceedings of 31st ICIS 2010 (2010)

6. Barjis, J.: Collaborative, Participative and Interactive Enterprise Modeling. In: Filipe, J., Cordeiro, J. (eds.) Enterprise Information Systems. LNBIP, vol. 24, pp. 651-662. Springer, Heidelberg (2009)

7. Ylimäki, T.: Potential Critical Success Factors for Enterprise Architecture. Journal of Enterprise Architecture 2(4), 29-40 (2006)

8. Lucke, C., Krell, S., Lechner, U.: Critical Issues in Enterprise Architecting - A Literature Review. In: Proceedings of the Americas Conference on Information (2010)

9. Gericke, A., Bayer, F., Kühn, H., Rausch, T., Strobl, R.: Der Lebenszyklus des Prozessmanagements. In: Bayer, F., Kühn, H. (eds.) Prozessmanagement für Experten, Springer, Heidelberg (2013)

10. Franz, P., Kirchmer, M.: Value-driven Business Process Management - The Value Switch for Lasting Competitive Advantage. McGraw-Hill (2012) 
11. Roth, S., Hauder, M., Farwick, M., Matthes, F., Breu, R.: Enterprise Architecture Documentation: Current Practices and Future Directions. In: 11th International Conference on Wirtschaftsinformatik (WI), Leipzig, Germany (2013)

12. Jeusfeld, M.A., Jarke, M., Nissen, H.W., Staudt, M.: ConceptBase: Managing Conceptual Models about Information Systems. In: Bernus, P., et al. (eds.) Handbook on Architectures of Information Systems, pp. 273-294. Springer, Berlin (2006)

13. Persson, A., Stirna, J.: Why Enterprise Modelling? An Explorative Study into Current Practice. In: Dittrich, K.R., Geppert, A., Norrie, M. (eds.) CAiSE 2001. LNCS, vol. 2068, pp. 465-468. Springer, Heidelberg (2001)

14. Proper, H., Verrijn-Stuart, A.A., Hoppenbrouwers, S.: On Utility-based Selection of Architecture-Modelling Concepts. In: 2nd AsiaPasific Conference on Conceptual Modelling (APCCM 2005) in New Castle, pp. 1-11. Australian Computer Society (2005)

15. Wolff, F.: Ökonomie multiperspektivischer Unternehmensmodellierung. IT-Controlling für modell-basiertes Wissensmanagement. Gabler, Wiesbaden (2008)

16. Horkoff, J., Yu, E.: Evaluating Goal Achievement in Enterprise Modeling - An Interactive Procedure and Experiences. In: Persson, A., Stirna, J. (eds.) PoEM 2009. LNBIP, vol. 39, pp. 145-160. Springer, Heidelberg (2009)

17. van der Raadt, B., Bonnet, M., Schouten, S., van Vliet, H.: The relation between EA effectiveness and stakeholder satisfaction. Journal of Systems and Software 83, 1954-1969 (2010)

18. Fassin, Y.: The Stakeholder Model Refined. Journal of Business Ethics 84, 113-135 (2009)

19. Lagerström, R., Saat, J., Franke, U., Aier, S., Ekstedt, M.: Enterprise Meta Modeling Methods - Combining a Stakeholder-Oriented and a Causality-Based Approach. In: Halpin, T., Krogstie, J., Nurcan, S., Proper, E., Schmidt, R., Soffer, P., Ukor, R. (eds.) Enterprise, Business-Process and Information Systems Modeling. LNBIP, vol. 29, pp. 381-393. Springer, Heidelberg (2009)

20. Niemi, E.: Enterprise Architecture Stakeholders - a Holistic View. In: Proceedings of AMCIS 2007, p. 41 (2007)

21. Espinosa, J.A., Armour, F., Boh, W.F.: Coordination in Enterprise Architecting: An Interview Study. In: Proceedings HICSS 2010, pp. 1-10 (2010)

22. Seppanen, V., Heikkila, J., Liimatainen, K.: Key Issues in EA-Implementation: Case Study of Two Finnish Government Agencies. In: Proceedings of the 2009 IEEE Conference on Commerce and Enterprise Computing, pp. 114-120. IEEE Computer Society (2009)

23. Morello, F.: Creating Incentive-Driven Tasks to Improve Knowledge Management in Sales Chain Relationships. In: Karagiannis, D., Reimer, U. (eds.) PAKM 2002. LNCS (LNAI), vol. 2569, pp. 87-96. Springer, Heidelberg (2002)

24. Wolff, F.: An Evaluation Framework for Enterprise Architecture Modelling. Enterprise Modelling and Information Systems Architectures 3(1), 48-61 (2008)

25. Bock, A., Kattenstroth, H., Overbeek, S.: Towards a modeling method for supporting the management of organizational decision processes. In: Modellierung 2014, pp. 49-64. Proceedings GI LNI P-225, Bonn (2014) 